\title{
Nuts and Cardiovascular Diseases: Focus on Brazil Nuts
}

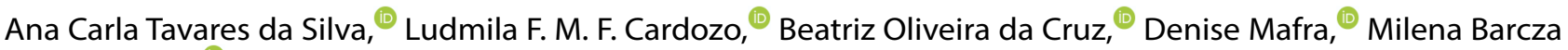
Stockler-Pinto

Fluminense Federal University (UFF), Niterói, RJ - Brazil

\section{Abstract}

Cardiovascular diseases (CVD) are the main cause of death globally and most CVD can be prevented by addressing their risk factors, such as an unhealthy diet. Many authors have studied the benefits of nut consumption on CVD. Nuts contain high amounts of vegetable protein, unsaturated fatty acids, dietary fibers, vitamins, minerals and many other bioactive compounds, like phytosterols and phenolic compounds, which are able to reduce cholesterol levels and promote antioxidant and anti-inflammatory effects, thereby reducing cardiovascular risks. This review aims to describe studies involving the consumption of nuts, including Brazil nuts and CVD risk factors with positive results in the improvement of lipid profile, glucose metabolism, vascular function, and inflammatory and oxidative stress biomarkers.

\section{Introduction}

Cardiovascular diseases (CVD) are the main cause of death globally: more people die annually from CVD than from any other cause. ${ }^{1}$ Multiple cardiovascular risk factors, including hyperlipidemia, hypertension, diabetes and smoking are associated with excessive production of reactive oxygen species and increased oxidative stress and inflammation, and promote vascular cell damage. Consequently, increased inflammation and

\section{Keywords}

Cardiovascular Diseases; Nuts; Seeds; Diet, High-Protein; Cholesterol; Anti-Oxidants; AntiInflammatory Agents. oxidative stress is considered the major mechanism of the pathogenesis of endothelial dysfunction. ${ }^{2}$

The use of bioactive compounds such as monounsaturated and polyunsaturated fatty acids, phenolic compounds and some minerals to reduce CVDrelated oxidative stress and inflammatory processes have been investigated. ${ }^{3}$ Nuts are known to contain high lipid content, mostly mono- (MUFA) and polyunsaturated fatty acids (PUFA). Together with others nutrients, MUFA and PUFA may promote plasma cholesterol reduction and exert an anti-oxidant and anti-inflammatory effect, thereby reducing cardiovascular risk factors. ${ }^{3-5}$

Edible nuts include tree nuts (almonds, hazelnuts, walnuts, pistachios, pine nuts, cashews, pecans, macadamias, Brazil nuts) and peanuts. They have a similar nutrient composition, containing high amounts of vegetable protein, unsaturated fatty acids, dietary fibers, vitamins, minerals and bioactive compounds, like phytosterols and phenolic compounds. ${ }^{6}$

Therefore, the present review aims to describe the effects of nut consumption, as a coadjutant therapy for prevention of cardiovascular diseases, with a special focus on Brazil nuts, considering the lack of studies on the direct effect of Brazil nuts on established cardiovascular risk factors.

\section{Methods}

A literature search was conducted using the PubMed / MEDLINE database for studies on the effects of nut consumption, including Brazil nuts, on CVD risk factors such as lipid profile, glucose metabolism, vascular function, inflammatory and oxidative stress biomarkers. The following MeSH terms were applied in the search: cardiovascular diseases/ brazil nuts/ 
coronary artery disease / atherosclerosis/ nuts / oxidative stress/inflammation.

Inclusion criteria for article selection were: full articles published in English; articles investigating the effects of the consumption of nuts on cardiovascular disease and risk factors; articles indexed in Pubmed / MEDLINE database in the last ten years.

\section{Nuts and cardiovascular disease}

Several studies have been conducted considering the beneficial association between nut consumption (Table 1) and CVD risk factors (Table 2)., ${ }^{3,7-16}$

Dose-response analysis of nut consumption and the risk of coronary artery disease (CAD) have been described, and a higher consumption of nuts was significantly associated with reduced risk of CAD when compared with a lower consumption. In fact, an increase in nut consumption by one serving per week significantly decreased the risk of CAD by $5 \%$, and the protective effect was associated with a consumption of two servings / week. ${ }^{7}$

A study that evaluated nut consumption and cardiovascular risk factors in the United States

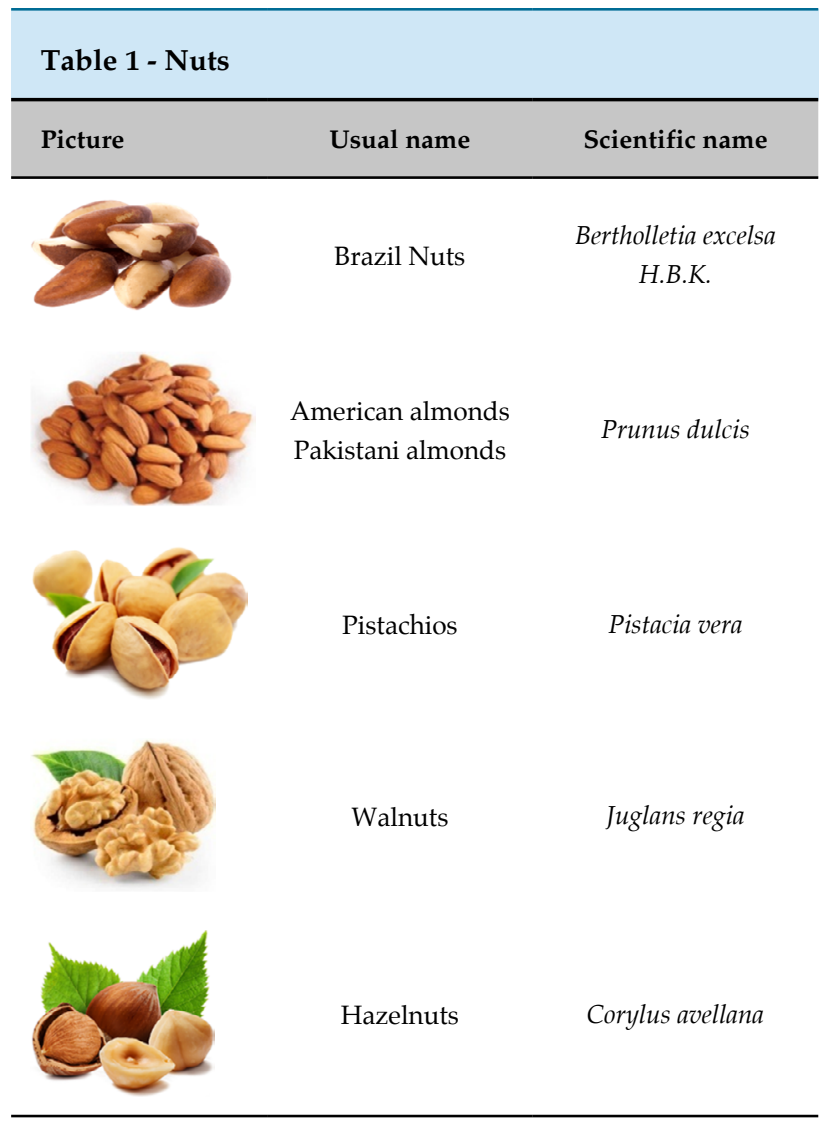

population, showed a mean usual intake of tree nuts of $44,3 \pm 1,6 \mathrm{~g} /$ day. Nut consumption was significantly associated with beneficial effects in body mass index, waist circumference, blood pressure, insulin resistance, lower chance of obesity and overweight and increase in high-density lipoprotein cholesterol (HDL-c) levels. ${ }^{8}$

The lipid profile in CAD patients and the consumption of almonds was assessed by Jamshed et al. ${ }^{9}$ In their study, participants were divided in three groups: non-intervention, Pakistani almonds and American almonds. After the consumption of $10 \mathrm{~g} /$ day of Pakistani or American almonds for 6 weeks, the authors observed an increase in HDL-c levels, and a decrease in triglycerides (TG), low-density lipoprotein cholesterol (LDL-c), very low density lipoprotein (VLDL), total cholesterol (TC) to HDL-c and LDL to HDL-c ratios, and in the atherogenic index (calculated by the non-HDL/ HDL-c ratio) in comparison with non-consumers. There were no significant differences in the cardiovascular risk factors evaluated between the Pakistani almond consumers and the American almond consumers. The authors concluded that consumption of almonds can improve lipid profile and could be used as an adjuvant in the treatment of dyslipidemias. ${ }^{9}$

Kasliwal et al., ${ }^{10}$ evaluated the effects of daily supplementation of $80 \mathrm{~g}$ of pistachios in shell, roasted and salted for three months and observed a significant increase in HDL-c and decrease in LDL-c, TC/HDL-c ratio and fasting blood glucose. Vascular function was also evaluated by measurement of the brachial artery flowmediated vasodilatation (BAFMD), and carotid femoral and brachial-ankle pulse wave velocity (cfPWV and baPWV, respectively). After supplementation, there was a significant reduction in left baPWV. These results demonstrated the positive effect of pistachios on the lipid profile and the vascular function in dyslipidemic adult patients. ${ }^{10}$

Sauder et al., ${ }^{11}$ evaluated the effects of $59 \mathrm{~g}-128 \mathrm{~g}$ of pistachios on lipid profile, glycemic control, inflammation and endothelial function in type-2 diabetes patients. After four weeks the authors observed that TC, TC/HDL-c ratio and TG, as well as fructosamine levels were significantly reduced. ${ }^{11}$

Damasceno et al., ${ }^{12}$ evaluated three types of diets in hypercholesterolemic subjects - a diet enriched with virgin olive oil ( 35 to $50 \mathrm{~g}$ daily), almonds ( 50 to $75 \mathrm{~g}$ daily) or walnuts (40 to $65 \mathrm{~g}$ daily) for four weeks. The amounts of each nutrient were calculated according to total energy intake. Among the three diets, almond-enriched diet 
Table 2 - Effects of nut consumption on cardiovascular risk factors

\begin{tabular}{|c|c|c|c|}
\hline Study population & Intervention & Duration & Main outcomes \\
\hline American adults $(14,386)^{8}$ & $\begin{array}{l}\geq 1 / 4 \text { ounce / day of tree nuts (almonds, } \\
\text { Brazil nuts, cashews, hazelnuts, } \\
\text { macadamias, pecans, pine nuts, } \\
\text { pistachios and walnuts) }\end{array}$ & $\begin{array}{l}2 \text { multiple pass } \\
\text { 24-h dietary recalls }\end{array}$ & $\begin{array}{c}\text { Decreased body mass index, waist } \\
\text { circumference, blood pressure, insulin } \\
\text { resistance } \\
\text { Increased HDL-c } \\
\text { Lowered chances of obesity and overweight }\end{array}$ \\
\hline $\begin{array}{l}\text { CAD patients with optimal } \\
\text { LDL-c and low HDL-c ( }(37)^{9}\end{array}$ & $\begin{array}{c}10 \mathrm{~g} / \text { day of Pakistan or American } \\
\text { almonds }\end{array}$ & 6 weeks & $\begin{array}{c}\text { Increased HDL-c } \\
\text { Decreased TG, LDL-c, VLDL-c, TC/HDL-c } \\
\text { and LDL/HDL-c ratio and atherogenic index }\end{array}$ \\
\hline $\begin{array}{l}\text { Indian dyslipidemic adults } \\
(60)^{10}\end{array}$ & $\begin{array}{l}80 \mathrm{~g} / \text { day of pistachios in shell, } \\
\text { roasted and salted }\end{array}$ & 12 weeks & $\begin{array}{c}\text { Increased HDL-c } \\
\text { Decreased LDL-c, TC/HDL-c ratio and } \\
\text { fasting blood glucose } \\
\text { Improved vascular function }\end{array}$ \\
\hline $\begin{array}{l}\text { Adults with well-controlled } \\
\text { type } 2 \text { diabetes }(30)^{11}\end{array}$ & $\begin{array}{l}\text { Roasted pistachios that provided } \\
20 \% \text { of daily energy ( } 59 \text { to } 128 \mathrm{~g} \text { ) }\end{array}$ & 4 weeks & $\begin{array}{c}\text { Decreased TC, TC/HDL-c ratio, TG and } \\
\text { fructosamine }\end{array}$ \\
\hline $\begin{array}{l}\text { Hypercholesterolemic } \\
\text { patients }(18)^{12}\end{array}$ & $\begin{array}{l}\text { Virgin olive oil ( } 35 \text { to } 50 \mathrm{~g} / \text { day), } \\
\text { almonds ( } 50 \text { to } 75 \mathrm{~g} / \text { day) and } \\
\text { walnuts ( } 40 \text { to } 6 \mathrm{~g} / \text { day) }\end{array}$ & 4 weeks & $\begin{array}{l}\text { Decreased TC, LDL-c, LDL/HDL-c ratio } \\
\text { (results were more expressive with the } \\
\text { almonds supplementation, possibly due to } \\
\text { the greater content of phytosterol) }\end{array}$ \\
\hline $\begin{array}{l}\text { Adults with metabolic } \\
\text { syndrome }(50)^{17}\end{array}$ & $\begin{array}{c}\text { Mixed raw nuts with skin }(15 \mathrm{~g} / \text { day } \\
\text { of walnuts, } 7.5 \mathrm{~g} / \text { day of almonds, } \\
7.5 \mathrm{~g} / \text { day of hazelnuts })\end{array}$ & 12 weeks & $\begin{array}{l}\text { Decreased DNA damage (measured by } \\
\text { 8-oxo-dG urinary excretion), inflammatory } \\
\text { biomarker (IL-6) }\end{array}$ \\
\hline $\begin{array}{l}\text { Subjects at increased } \\
\text { cardiovascular risk }(22)^{19}\end{array}$ & $\begin{array}{l}300 \mathrm{~g} \text { of walnut paste-enriched meat / } \\
\text { week (containing 20\% walnut paste) }\end{array}$ & 5 weeks & $\begin{array}{l}\text { Decreased sVCAM, sICAM and Leukotriene } \\
\text { B4 }\end{array}$ \\
\hline $\begin{array}{l}\text { Hypercholesterolemic } \\
\text { volunteers }(21)^{20}\end{array}$ & 49 to $86 \mathrm{~g}$ / day hazelnut enriched diet & 4 weeks & $\begin{array}{c}\text { Decreased CRP and sVCAM } \\
\text { Improved endothelial dysfunction }\end{array}$ \\
\hline $\begin{array}{l}\text { HDL-c: high-density lipoprote } \\
\text { cholesterol; TC: total cholester } \\
\text { molecule; CRP: C-reactive pro }\end{array}$ & $\begin{array}{l}\text { holesterol; TG: trygliceridies; LDL-c: low } \\
\text { L-6: interleukin 6; sVCAM: soluble vascl }\end{array}$ & $\begin{array}{l}\text { asity lipoprotein chole } \\
\text { cell adhesion molecul }\end{array}$ & $\begin{array}{l}\text { ol; VLDL-c: very low-density lipoprotein } \\
\text { ICAM: soluble intercellular cell adhesion }\end{array}$ \\
\hline
\end{tabular}

showed to have the greatest hypocholesterolemic effect, which could be explained by the presence the higher content of phytosterol in almonds compared with olive oil and walnuts. ${ }^{12}$

One of the hypothesis for the hypocholesterolemic effect of nuts is their high amounts of phytosterols. Phytosterols are non-nutritive components of plants that play an important structural role in membranes, where they serve to stabilize phospholipid bilayers just as cholesterol does in animal cell membranes. ${ }^{6}$ These compounds are able to displace cholesterol from intestinal micelles thereby reducing its absorption and leading to a reduction in LDL-C and TC (Figure 1).,13

Nuts are also an important factor to modulate hypertension, since MUFA and PUFA are able to reduce serum levels of thromboxane $\mathrm{A} 2$, which is a vasoconstrictor. ${ }^{4}$ In addition, the mineral content of nuts develops a key role in hypertension, as magnesium found in nuts stimulates the production of nitrous oxide, a vasodilator, and blocks the calcium channels, promoting vasodilatation. Furthermore, potassium can modulate the extracellular fluid volume reducing peripheral vascular resistance (Figure 1). ${ }^{4,14}$ A review study investigating the association between nut consumption, hypertension and endothelial dysfunction showed that there are insufficient epidemiological data associating nuts with the prevention of hypertension, ${ }^{14}$ which was reported in only two prospective studies. The first study was a prospective cohort conducted by Djousse et al., ${ }^{15}$ with participants from the Physicians Health Study I, who were free of hypertension at 


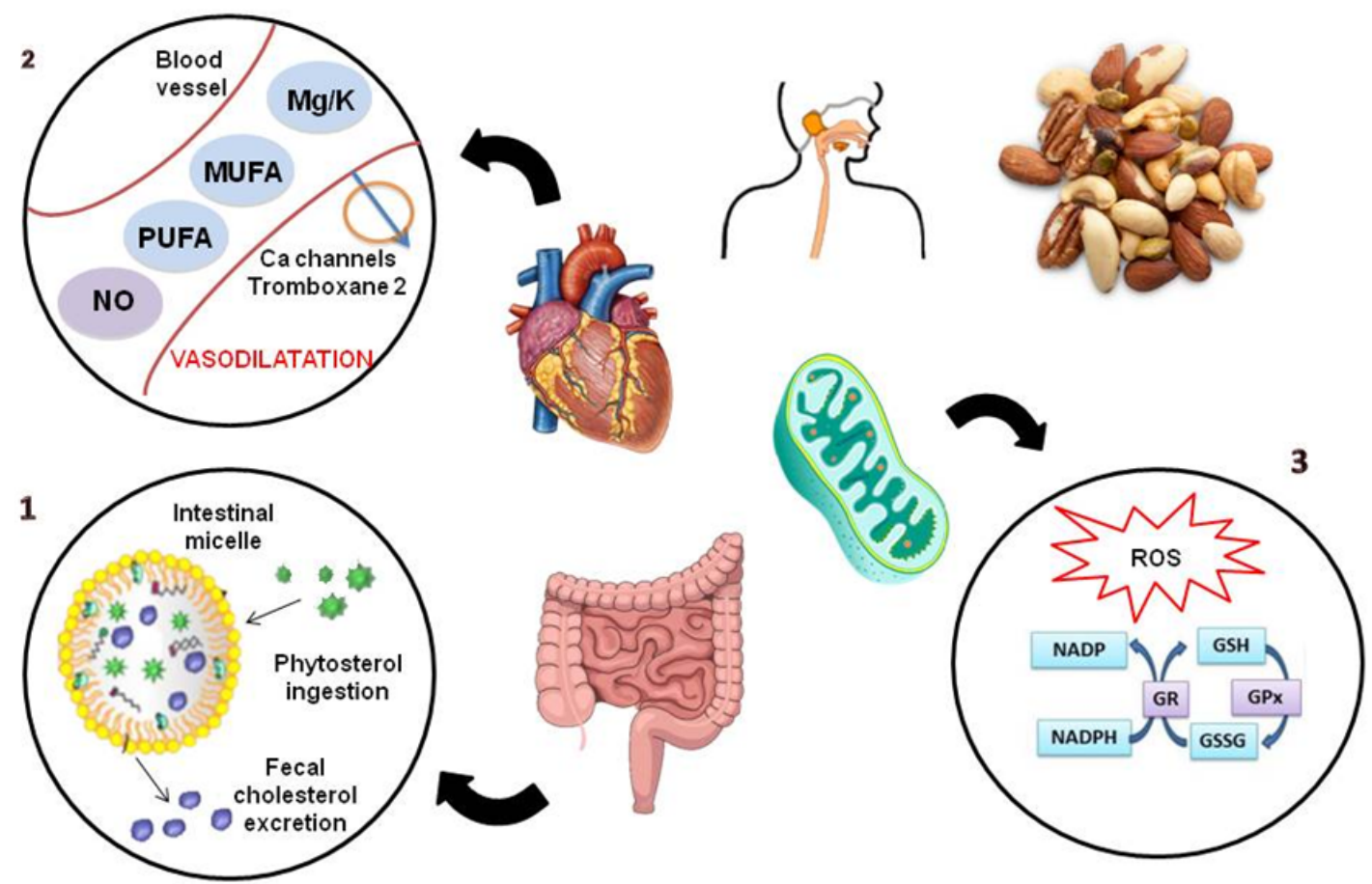

Figure 1 - Effects of nut consumption. The hypocholesterolemic effect is related to the rich content of phytosterols, non-nutritive components of all plants, able to displace cholesterol from intestinal micelles, reducing its absorption. Nuts are involved in the modulation of hypertension due to their high content of MUFA and PUFA, and which can reduce serum levels of thromboxane-A2, an important vasoconstrictor. Nuts are also rich in magnesium, stimulating the production of nitrous oxide and blockage of calcium channels, thus promoting vasodilatation. Concerning the antioxidant properties of Brazil nuts, its high content of selenium is particularly due to its presence in the glutathione peroxidase, an important enzyme that prevents the accumulation of reactive species of oxygen.

baseline. The authors showed a lower incidence of hypertension in usual consumers of nuts compared to non-consumers, although they did not consider the consumption of salt and body weight changes, two major factors associated with the risk of hypertension. The other study, conducted with Spanish university graduates followed-up for a median of 4.3 years in the SUN cohort, did not observe any association between nut consumption and the incidence of hypertension, after adjustment for several confounders. ${ }^{15,16}$

The effects of nuts on novel coronary heart disease risk factors including oxidative stress, inflammation and vascular reactivity have been evaluated, ${ }^{6}$ and showed to promote beneficial effects on vascular reactivity by decreasing endothelial activation and improving flow-mediated vasodilatation ${ }^{2}$ and nitric oxide-induced endothelial relaxation. As nuts are an excellent source of antioxidants, it's no coincidence that they are related to an improvement of the oxidative status. ${ }^{6}$
A study that evaluated oxidative stress and endothelial function in metabolic syndrome patients showed that the consumption of $30 \mathrm{~g}$ of mixed nuts for 12 weeks reduced significantly DNA damage (measured by the 8-oxo-dG urinary excretion). ${ }^{17}$ Inflammatory biomarkers were also assessed and showed a significant decrease in interleukin-6 (IL-6) after nut consumption compared with the control group. After adjustment for changes in body weight, this statistical significance was reduced; however, there was still a borderline improvement in inflammatory markers in these patients. ${ }^{18}$

The effect of walnuts on inflammatory biomarkers in subjects with cardiovascular risk was also assessed in a cross-over study. Men and postmenopausal women (age $\geq 45$ years and $\geq 50$ years, respectively) were included in the study. Participants were obese or overweight and had one or more of the following risk factors: smoking habits, hypertension, familial hypercholesterolemia and type 1 diabetes. Intervention consisted of two 5-week 
experimental period: during one period, participants consumed a walnut paste-enriched diet and a low-fat meat (LM) diet during the other. In the first group, there was a significant decrease of soluble vascular and intercellular cell adhesion molecules (sVCAM and sICAM, respectively) and leukotriene $\mathrm{B} 4$ (LTB4) compare to the baseline and also compared to the LM diet, improving the proinflammatory status and endothelium damage. ${ }^{19}$

A study evaluated the effects of hazelnut-enriched diet on cardiovascular biomarkers in hypercholesterolemic subjects. The diets were applied to the same group and divided in three periods of four weeks each: control diet I, preconized by the National Cholesterol Education Program adult treatment panel (ATP) III step 2 diet (7\% energy from SFA and $200 \mathrm{mg} /$ dietary cholesterol), a hazelnut-enriched diet that corresponded to 18 to $20 \%$ of the dietary daily energy intake ( 49 to $86 \mathrm{~g} /$ day) and control diet II, that was equivalent to control diet I. The association of the hazelnut diet with measures of endothelial dysfunction assessed by the flow-mediated dilatation (FMD) technique, showed a significant improvement, besides a significant negative correlation with sVCAM-1 and the enriched hazelnut diet. Among the inflammatory biomarkers, C-reactive protein (CRP) and sVCAM-1 showed a significant reduction during the hazelnut diet. The authors demonstrated that the improvement on biochemical parameters and endothelial dysfunction after the consumption of a hazelnut-enriched diet nearly returned to basal levels after the control diet II, showing the importance of a regular consumption. ${ }^{20}$

The recent publication in the Journal of the American College of Cardiology about nutrition trends for prevention and treatment of atherosclerotic cardiovascular diseases recommends the consumption of $30 \mathrm{~g} /$ day of nuts, regarding portion control to avoid weight gain. ${ }^{21}$
Among the nuts, it is worth mentioning the Brazil nuts, as being the largest of the commonly consumed nuts from the Brazil nut tree (Bertholletia excelsa), which is a native of South America. The Brazil nut tree was originally discovered growing in hard, well-drained soil along the Amazon River in countries such as Brazil, Peru, Colombia, Venezuela, and Ecuador. Recent studies have been conducted associating Brazil nuts with many health benefits, mainly including cholesterol-lowering effects, antioxidant activity, and antiproliferative effects. ${ }^{22}$

\section{Brazil nuts}

Brazil nuts are the main source of selenium, constituents of selenoproteins, such as glutathione peroxidase (GPx) that promote cardiovascular benefits because of their antioxidant properties (Figure 1). Brazil nuts are also a good source of unsaturated fatty acids, with a high content of MUFAs $(\sim 50 \%)$, proteins, fiber, magnesium, phosphorus, thiamin, niacin, vitamin E, vitamin $B$, calcium, iron, potassium, zinc and copper. ${ }^{22,23}$ (Tables $3^{24,25}$ and 4).

Earlier studies involving the consumption of Brazil nuts and its effects on cardiovascular risk factors showed an improvement in antioxidant status and lipid biomarkers. ${ }^{26,27}$ A randomized study conducted with 59 New Zealand adults, demonstrated a significant increase in plasma selenium and GPx activity in whole blood after the consumption of two Brazil nuts/day (corresponding to $53 \mu \mathrm{g}$ of selenium) for 12 weeks, being as effective as the supplementation with $100 \mu \mathrm{g}$ of selenium seleniomethionine. ${ }^{26}$ A significant increase in plasma selenium was also seen in the study by Strunz et al., ${ }^{27}$ with 15 normolipidemic subjects after the consumption of $45 \mathrm{~g}$ / day (about 11 units) of Brazil nuts for 15 days. Concerning lipid abnormalities, although the lipid plasma profile did not alter, it was observed an

Table 3 - Nutritional composition of Brazil nuts in macronutrients, micronutrients and polyphenols (per $5 \mathrm{~g}$ )

\begin{tabular}{lccccccccccc}
\hline Nuts & $\begin{array}{c}\text { Energy } \\
(\mathbf{k c a l})\end{array}$ & $\begin{array}{c}\text { Protein } \\
(\mathrm{g})\end{array}$ & $\begin{array}{c}\text { Fibre } \\
(\mathrm{g})\end{array}$ & $\begin{array}{c}\text { Fat } \\
(\mathrm{g})\end{array}$ & $\begin{array}{c}\text { SFA } \\
(\mathrm{g})\end{array}$ & $\begin{array}{c}\text { MUFA } \\
(\mathrm{g})\end{array}$ & $\begin{array}{c}\text { PUFA } \\
(\mathrm{g})\end{array}$ & $\begin{array}{c}\text { Vitamin } \\
(\mathbf{m g})\end{array}$ & $\begin{array}{c}\text { Zinc } \\
(\mathbf{m g})\end{array}$ & $\begin{array}{c}\text { Selenium } \\
(\mu \mathrm{g})\end{array}$ & $\begin{array}{c}\text { Total } \\
\text { polyphenols } \\
(\mathbf{m g})\end{array}$ \\
\hline $\begin{array}{l}\text { Brazil } \\
\text { nuts }\end{array}$ & 36,7 & 0,75 & 0,4 & 3,53 & 0,81 & 1,19 & 1,22 & 0,28 & 0,2 & 290,5 & 12,2 \\
\hline
\end{tabular}

SFA: saturated fatty acids; MUFA: monounsaturated fatty acids; PUFA: polyunsaturated fatty acids Sources: Ros E., ${ }^{3}$ Stockler-Pinto et al, $2010,{ }^{24}$ US Department of Agriculture Nutrient Data Base. ${ }^{25}$ 
Table 4 - Effects of Brazil nuts consumption

\begin{tabular}{|c|c|c|c|}
\hline Study population & $\begin{array}{l}\text { Intervention } \\
\text { (Brazil nuts) }\end{array}$ & Duration & Main outcomes \\
\hline New Zealand adults $(59)^{26}$ & $\begin{array}{c}2 \text { units } \\
\text { (about } 10 \mathrm{~g} \text { ) }\end{array}$ & 12 weeks & $\begin{array}{l}\text { Increased Plasma Se } \\
\text { Increased GPx activity }\end{array}$ \\
\hline Normolipidemic subjects $(15)^{27}$ & $45 \mathrm{~g}$ & 15 days & $\begin{array}{l}\text { Increased Plasma Se } \\
\text { Increased Reception of cholesteryl } \\
\text { esters by HDL }\end{array}$ \\
\hline Healthy volunteers $(10)^{23,28}$ & 5,20 or $50 \mathrm{~g}$ & 1 day & $\begin{array}{c}\text { Decreased LDL-c } \\
\text { Increased HDL-c } \\
\text { Decreased AR index } \\
\text { Increased Plasma Se } \\
\text { Decreased IL-1, IL-6, TNF } \alpha, \text { INF } \gamma \\
\text { Increased IL-10 }\end{array}$ \\
\hline Obese Adolescents $(17)^{29}$ & 15 to $25 \mathrm{~g}$ & 16 weeks & $\begin{array}{c}\text { Decreased LDL-c } \\
\text { Decreased LDL-ox } \\
\text { Decreased TC } \\
\text { Decreased Tryglicerides } \\
\text { Increased Plasma Se } \\
\text { Increased RBCV }\end{array}$ \\
\hline Obese Women $(37)^{30}$ & $5 \mathrm{~g}$ & 8 weeks & $\begin{array}{c}\text { Increased HDL-c } \\
\text { Decreased AR Index } \\
\text { Increased Erythrocyte Se } \\
\text { Increased Plasma Se } \\
\text { Increased GPx activity }\end{array}$ \\
\hline $\begin{array}{l}\text { Dialysis patients }(40)^{31},(21)^{32,33} \text {, } \\
(13)^{34}\end{array}$ & $5 \mathrm{~g}$ & 12 weeks & $\begin{array}{c}\text { Decreased LDL-c } \\
\text { Increased HDL-c- } \\
\text { Decreased AR Index } \\
\text { Decreased 8-isoprostane,8-OHdG } \\
\text { Increased Plasma Se } \\
\text { Increased GPx activity } \\
\text { IL-6, TNF } \alpha, \text { MDA, CRP, Nf-kB- } \\
\text { Decrease } \\
\text { Increased Nfr2 }\end{array}$ \\
\hline $\begin{array}{l}\text { Hypertenses and } \\
\text { dyslipidemics patients }(91)^{35,36}\end{array}$ & $13 \mathrm{~g}$ & 12 weeks & $\begin{array}{l}\text { Decreased LDL-ox } \\
\text { Decreased Apo A1 } \\
\text { Decreased TC } \\
\text { Increased Plasma Se } \\
\text { Increased GPx activity } \\
\text { Increased Nitric oxide }\end{array}$ \\
\hline \multicolumn{4}{|c|}{$\begin{array}{l}\text { LDL-c: low-density lipoprotein cholesterol; LDL-ox: oxidized low-density lipoprotein; HDL-c: high-density lipoprotein cholesterol; AR index: atherogenic } \\
\text { index ratio; IL: interleukin; TNFa: tumor necrosis factor alpha; INFy: interferon gamma; TC: total cholesterol; RBCV: red blood cell velocity; GPx: } \\
\text { glutathione peroxidase; 8-OHdG: 8-hydroxy-2-deoxyguanosine; MDA: malonilaldehyde; CRP: C-reactive protein; Nf-kB: factor nuclear kappa B; Nfr2: } \\
\text { nuclear factor erythroid 2-related factor 2; Apo A1: apoliprotein A1. }\end{array}$} \\
\hline
\end{tabular}

increased reception of cholesteryl ester by HDL, which positively contributes to the nonatherogenic reverse cholesterol pathway. ${ }^{27}$

Studies involving healthy volunteers analyzed the lipid profile and inflammatory biomarkers after a single consumption of $20 \mathrm{~g}$ of Brazil nuts (about four units) and showed that Brazil nuts were able to significantly increase the levels of HDL-c and lower LDL-c and significantly decrease the atherogenic ratio index (AR index). On the other hand, serum triglycerides and total cholesterol did 
not reduce significantly. Plasma selenium significantly increased after the ingestion of 5,20 and $50 \mathrm{~g}$ of nuts, but its concentrations were not significantly different between the different levels of ingestion. The levels of inflammatory biomarkers IL-1, IL-6, tumor necrosis factor- alpha (TNF- $\alpha$ ) and interferon gamma (IFN- $\gamma$ ) significantly decrease and the levels of IL-10 significantly increased after the ingestion of 20 or $50 \mathrm{~g}$ of nuts. Other inflammatory and oxidative stress biomarkers, such as C-reactive protein, erythrocyte glutathione peroxidase activity, DNA damage and $\delta$-aminolevulinate dehydratase activity, did not show significantly results. ${ }^{23,28}$

Obese female adolescents were also evaluated after consumption of 15 to $25 \mathrm{~g}$ Brazil nuts daily during 16 weeks and compared with a placebo group (PG). The authors showed a significant reduction of TC, LDL-c and TG in the Brazil nuts group (BNG). Concerning the antioxidant capacity biomarkers, the oxidized LDL (LDL-ox) levels significantly decrease in BNG compared to PG after the supplementation. Plasma selenium and red blood cell velocity (RBCV), a marker of microvascular function, showed a significant increase after the supplementation, demonstrating the positive effect of Brazil nuts on lipid profile and microvascular function in this population. ${ }^{29}$

Similar results were described in a study with obese women; the consumption of one Brazil nut per day for 8 weeks, significantly increased HDL-c and decreased AR index, calculated through Castelli I and II indexes. Besides, a significant increase by $138 \%$ in plasma selenium status, and $46 \%$ in GPx activity were found after the consumption of Brazil nuts. ${ }^{30}$

In studies with hemodialysis patients, after 3 months of supplementation with one Brazil nut/day, there was a significant decrease in LDL-c and AR index, Castelli I and Castelli II, as well as an expressive increase in HDL-c. However, no significant changes were found in total cholesterol and TG levels. There was also a significant increase in plasma selenium and GPx activity. Regarding the oxidative DNA damage and lipid peroxidation, 8-hydroxy-2-deoxyguanosine (8OHdG), malonilaldehyde (MDA) and 8-isoprostane showed a significant decrease, as well the inflammatory markers, IL-6, TNF $\alpha, C R P$, and factor nuclear kappa $\mathrm{B}(\mathrm{Nf}-\kappa \mathrm{B})$ an important regulator of the transcription factor. Subsequently the authors evaluated the nuclear factor erythroid 2-related factor 2 (Nfr2), which plays an important role in the activation of several pathways against cellular oxidative stress and $\mathrm{NAD}(\mathrm{P}) \mathrm{H}$ :quinone oxide reductase 1 (NQO1), and phase II detoxifying enzymes, which also decreased significantly after the

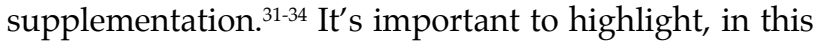
case, that most patients had selenium deficiency before the supplementation, which was reversed after the consumption of one Brazil nut per day.

Hypertensive and dyslipidemic patients were also studied after the supplementation of $13 \mathrm{~g} /$ day of granulated Brazil nut for three months. The results showed a significant increase in selenium plasma, GPx activity and decrease in LDL-ox. ${ }^{35}$ The microvascular endothelial function was also assessed, showing a significant increase in nitric oxide, with no change in systemic microvascular reactivity or density. ${ }^{36}$ Concerning the lipid profile, total cholesterol and apolipoprotein A1 (Apo A1) significantly decrease compared with pre-supplementation. ${ }^{37}$

Other studies evaluating Brazil nut supplementation were described in the review from Cardoso et al. ${ }^{38}$ A study conducted with children that received 15 to $30 \mathrm{~g}$ (3 to 6 units) of Brazil nuts three days per week showed a significant excess of selenium intake, combined with high levels of selenium in plasma, erythrocytes, urine, hair and nails, with no signs of selenosis, though. ${ }^{39}$ Another study involved older patients with mild cognitive impairment, and after the supplementation of one Brazil nut during six months, it was observed an improvement in selenium status, with a significant increase in plasma, erythrocyte and GPx activity, as well as an improvement in performance in cognitive tests. ${ }^{40}$ The potential effect of Brazil nut regarding the development of colorectal cancer was also investigated, and after the supplementation of six nuts for six weeks, the selenium levels increased in plasma with upregulated expression of genes associated with selenoproteins (SePP) and decreased rectal gene expression of $\beta$-catenin, biomarkers related to colorectal oncogenesis. ${ }^{41}$

As previously discussed, Brazil nut consumption is effective in improving lipid profile, and inflammatory and oxidative stress biomarkers in different populations, including healthy subjects, obese women, and hemodialysis patients. This review showed the vast benefits of the consumption of nuts on cardiovascular risk factors and drew attention to the lack of studies showing the effects of Brazil nuts in this regard.

\section{Conclusion}

The nutritional composition of nuts, abundant in unsaturated fatty acids, antioxidant minerals and 
phenolic compounds, play a significant role in the reduction of inflammation, oxidative stress and lipid profile, making them important alternatives to reduce the risks of chronic diseases.

\section{Acknowledgements}

This study was supported by Fundação de Amparo à Pesquisa do Estado do Rio de Janeiro (FAPERJ) and Coordenação de Aperfeiçoamento de Pessoal de Nível Superior (CAPES) - Finance Code 001.

\section{Author contributions}

Conception and design of the research: Silva ACT, Cardozo LFMF, Cruz BO, Mafra D, Stockler-Pinto MB. Acquisition of data: Silva ACT, Cardozo LFMF, Stockler-Pinto MB. Analysis and interpretation of the data: Silva ACT, Cardozo LFMF, Cruz BO, Mafra D, Stockler-Pinto MB. Statistical analysis: Stockler-Pinto MB. Obtaining financing: Stockler-Pinto MB. Writing of the manuscript: Silva ACT, Cardozo LFMF, StocklerPinto MB. Critical revision of the manuscript for

\section{References}

1. World Health Organization (WHO). Cardiovascular diseases. 2015. [Cited in 2016 Apr 10]. Available from: http://www.who.int/ mediacentre/factsheets/fs317/en.

2. Grover-Paez F, Zavalza-Gomez AB. Endothelial dysfunction and cardiovascular risk factors. Diabetes Res Clin Pract. 2009;84(1):1-10.

3. Ros E. Nuts and CVD. Br J Nutr. 2015; 113 Suppl 2:S111-20.

4. Souza RG, Gomes AC, Naves MM, Mota JF. Nuts and legume seeds for cardiovascular risk reduction: scientific evidence and mechanisms of action. Nutr Rev. 2015;73(6):335-47.

5. Alexiadou K, Katsilambros N. Nuts: anti-atherogenic food? Eur J Intern Med. 2011;22(2):141-6.

6. Ros E. Health benefits of nut consumption. Nutrients. 2010;2(7):652-82.

7. Ma L, Wang F, Guo W, Yang H, Liu Y, Zhang W. Nut consumption and the risk of coronary artery disease: a dose-response meta-analysis of 13 prospective studies. Thromb Res. 2014;134(4):790-4.

8. $\mathrm{O}^{\prime}$ Neil C, Fulgoni VL, Nicklas TA. Tree nut consumption is associated with better adiposity measures and cardiovascular and metabolic syndrome health risk factors in U.S. Adults: NHANES 2005-2010. Nutr J. 2015;14:64-72.

9. Jamshed H, Sultan FA, Igbal R, Gilani AH. Dietary almonds increase serum HDL cholesterol in coronary artery disease patients in a randomized controlled trial. J Nutr. 2015:145(10):2287-92.

10. Kasliwal RR, Bansal Mehrotra R, Yeptho KP, Trehan N. Effect of pistachio nut consumption on endothelial function and arterial stiffness. Nutrition. 2015;31(5):678-85.

11. Sauder KA, McCrea CE, Ulbrecht JS, Kris-Etherton PM, West SG. Effects of pistachios on the lipid/lipoprotein profile, glycemic control, intellectual content: Silva ACT, Cardozo LFMF, Cruz BO, Mafra D, Stockler-Pinto MB.

\section{Potential Conflict of Interest}

No potential conflict of interest relevant to this article was reported.

\section{Sources of Funding}

This study was funded by Fundação de Amparo à Pesquisa do Estado do Rio de Janeiro (FAPERJ) and Coordenação de Aperfeiçoamento de Pessoal de Nível Superior (CAPES).

\section{Study Association}

This study is not associated with any thesis or dissertation work.

\section{Ethics approval and consent to participate}

This article does not contain any studies with human participants or animals performed by any of the authors. inflammation, and endothelial function in type 2 diabetes: a randomized trial. Metabolism. 2015;64(11):1521-9.

12. Damasceno NR, Perez-Heras A, Serra M, Cofa M, Sala-Vila A, SalasSalvado J, et al. Crossover study of diets enriched with virgin olive oil, walnuts or almonds: effects on lipids and other cardiovascular risk markers. Nutr Metab Cardiovasc Dis. 2011 Jun;21 Suppl 1:S14-20.

13. Del Gobbo LC, Falk MC, Feldman R, Lewis K, Mozaffarin D. Are phytosterols responsible for the low-density lipoprotein-lowering effects of tree nuts? J Am Coll Cardiol. 2015;65(25):2764-70.

14. Casas-Agustench P, Lopez-Uriarte P, Ros E, Mulló M, Salas-Salvado J. Nuts, hypertension and endothelial function. Nutr Metab Cardiovasc Dis. 2011;21 Suppl 1:S21-33.

15. Djoussé L, Rudich T, Gaziano JM. Nut consumption and risk of hypertension in US male physicians. Clin Nutr. 2009;28(1):10-4.

16. Martínez-Lapiscina EH, Pimenta AM, Beunza JJ, Bes-Rastrollo M, Martínez JA, Martínez-González MA. Nut consumption and incidence of hypertension: the SUN prospective cohort. Nutr Metab Cardiovasc Dis. 2010;20(5):359-65

17. Lopez-Uriarte P, Nogués R, Saez G, Bulló M, Romeu M, Masana L, et al. Effect of nut consumption on oxidative stress and the endothelial function in metabolic syndrome. Clin Nutr. 2010;29(3):373-80.

18. Casas-Agustench P, Lopez-Uriarte P, Bulló M, Ros E, Cabré-Vila JJ, SalasSalvadó J. Effects of one serving of mixed nuts on serum lipids, insulin resistance and inflammatory markers in patients with the metabolic syndrome. Nutr Metab Cardiovasc Dis. 2011;21(2):126-35.

19. Canales A, Sanchez-Muniz FJ, Bastida S, Librelotto J, Nus M, Corella D, et al. Effect of walnut-enriched meat on the relationship between VCAM, ICAM, and LTB4 levels and PON-1 activity in ApoA4 360 and PON-1 allele carriers at increased cardiovascular risk. Eur J Clin Nutr. 2011;65(6):703-10. 
20. Orem A, Yucesan FB, Orem C, Akcan B, Kural BV, Alasalvar C, et al. Hazelnut-enriched diet improves cardiovascular risk biomarkers beyond a lipid-lowering effect in hypercholesterolemic subjects. J Clin Lipidol. 2013;7(2):123-31.

21. Freeman AM, Morris PB, Barnard N, Esselstyn CB, Ros E, Agaston A, et al. Trending cardiovascular nutrition controversies. J Am Coll Cardiol. 2017;69(9):1172-87.

22. Yang J. Brazil nuts and associated health benefits: a review. Food Sci Technol. 2009;42(10):1573-80.

23. Colpo E, Vilanova CD, Brenner Reetz LG, Medeiros Frescura Duarte MM, Farias IL, Irineu Muller E, et al. A single consumption of high amounts of the Brazil nuts improves lipid profile of healthy volunteers. J Nutr Metab. 2013;2013:653185.

24. Stockler-Pinto MB, Mafra D, Farage NE, Boaventura GT, Cozzolino SM. Effect of Brazil nut supplementation on the blood levels of selenium and glutathione peroxidase in hemodialysis patients. Nutrition. 2010;26(11-12):1065-9.

25. US Department of Agriculture Nutrient Data Base. [Dited in 2017 Apr 14]. Available from: https://ndb.nal.usda.gov/ndb/search/list.

26. Thomson CD, Chisholm A, McLachlan SK, Campbell JM. Brazil nuts: An effective way to improve selenium status. Am J Clin Nutr. 2008;87(2):379-84.

27. Strunz CC, Oliveira TV, Vinagre JC, Lima A, Cozzolino S, Maranhao RC. Brazil nut ingestion increased plasma selenium but had minimal effects on lipids, apolipoproteins, and high-density lipoprotein function in human subjects. Nutr Res. 2008;28(3):151-5.

28. Colpo E, Dalton D A Vilanova C, Reetz LG, Duarte MM, Farias IL, Meinerz DF, et al. Brazilian nut consumption by healthy volunteers improves inflammatory parameters. Nutrition. 2014;30(4):459-65.

29. Maranhão PA, Kraemer-Aguiar LG, de Oliveira CL, Kuschnir MC, Vieira YR, Souza MG, et al. Brazil nuts intake improves lipid profile, oxidative stress and microvascular function in obese adolescents: a randomized controlled trial. Nutr Metab (Lond). 2011;8(1):32.

30. Cominetti C, de Bortoli MC, Garrido AB Jr, Cozzolino SM. Brazilian nut consumption improves selenium status and glutathione peroxidase activity and reduce atherogenic risk in obese women. Nutr Res. 2012;32(6):403-7.

31. Stockler-Pinto MB, Mafra D, Moraes C, Lobo J, Boaventura GT, Farage NE, et al. Brazil nut (Bertholletia excelsa, H.B.K.) improves oxidative stress and inflammation biomarkers in hemodialysis patients. Biol Trace Elem Res. 2014;158(1):105-12.

32. Stockler-Pinto MB, Lobo J, Moraes C, Leal VO, Farage NE, Rocha $\mathrm{AV}$, et al. Effect of Brazil nut supplementation on plasma levels of selenium in hemodialysis patients: 12 months of follow-up. J Ren Nutr. 2012;22(4):434-9.

33. Stockler-Pinto MB, Malm O, Moraes C, Farage NE, Silva WS, Cozzolino $\mathrm{SM}$, et al. A follow-up study of the chronic kidney disease patients treated with Brazil nut: focus on inflammation and oxidative stress. Biol Trace Elem Res. 2014;163(1-2):67-72.

34. Cardozo LF, Stockler-Pinto MB, Mafra D. Brazil nut consumption modulates Nrf2 expression in hemodialysis patients: a pilot study. Mol Nutr Food Res. 2016;60(7):1719-24.

35. Huguenin GV, Oliveira GM, Moreira AN, Saint 'Pierre TD. Improvement of antioxidant status after Brazil nut intake in hypertensive and dyslipidemic subjects. Nutr J. 2015;14:54.

36. Huguenin GV, Moreira AS, Siant'Pierre TD, Gonçalves RA, Rosa G, Oliveira GM, et al. Effects of dietary supplementation with Brazil nuts on microvascular endothelial function in hypertensive and dyslipidemic patients: a randomized crossover placebo-controlled trial. Microcirculation. 2015;22(8):687-99.

37. Carvalho RF, Huguenin GV, Luiz RR, Moreira AS, Oliveira GM, Rosa G. Intake of partially defatted Brazil nut flour reduces serum cholesterol in hypercholesterolemic patients- a randomized controlled trial. Nutr J. 2015 Jun 16;14:59.

38. Cardoso BR, Duarte GB, Reis BZ, Cozzolino SM. Brazil nuts: nutritional composition, health benefits and safety aspects. Food Res Int. 2017;100(Pt 2):9-18.

39. Martens IB, Cardoso BR, Hare DJ, Niedzwiecki MM, Lajolo FM, Martens A, et al. Selenium status in preschool children receiving a Brazil nutenriched diet. Nutrition. 2015;31(11-12):1339-43.

40. Rita Cardoso B, Apolinário D, da Silva Bandeira V, Busse AL, Magaldi RM, Jacob-Filho W, et al. Effects of Brazil nut consumption on selenium status and cognitive performance in older adults with mild cognitive impairment: a randomized controlled pilot trial. Eur J Nutr. 2016;55(1):107-16

41. Hu Y, McIntosh GH, Leu RK, Somashekar R, Meng XQ, Gopalsamy G, et al. Supplementation with Brazil nuts and green tea extract regulates targeted biomarkers related to colorectal cancer risk in humans. Br J Nutr. 2016;116(11):1901-11. 